\title{
Investigation research the new rural cooperative medical care security system
}

\author{
Jinting $\mathrm{Wu}^{1, \mathrm{a}}$, Jiapeng $\mathrm{Liu}^{1, \mathrm{~b}}$, Jianpeng $\mathrm{Xie}^{1, \mathrm{c}}$, Qianghui Ying ${ }^{1, \mathrm{~d}}$, \\ Huanhuan Shao ${ }^{1, \mathrm{e}}$, Hao Zhou ${ }^{1, \mathrm{f}}$ \\ ${ }^{1}$ School of Economics and Management, China Jiliang University, Hangzhou, 31018, China \\ aemail: 601674149@qq.com, bemail: jpliu@cjlu.edu.cn, 'email:454801015@qq.com \\ demail: 784010719@qq.com, ${ }^{\mathrm{e} e m a i l}$ :498760826@qq.com, ${ }^{\mathrm{f} e m a i l: 359186035 @ q q . c o m}$
}

Keywords: New rural cooperative medical care system; Current situation investigation; Influencing factors analysis; Policy recommendations

\begin{abstract}
Through the three city in Zhejiang Province a total of six rural villagers investigation, through various indicators objectively reflected at this stage of the rural residents participation intention and the impact of the new cooperative medical villagers decide whether participation factors. From many factors extracted from the personal economic status, psychological factors, the sense of participation, local hospital of new rural cooperative medical care system of credibility, propaganda, the new rural cooperative medical system and improve the level of six factors. Through multiple linear regression analysis on participation intention for quantitative analysis, explain each factor on participation intention is the influence and its size. The status quo in the new rural cooperative medical insurance people to understand the analysis, and to enhance the public participation will have important significance. To provide the reference for solving the problems in the process of participation and improve the participation willingness.
\end{abstract}

\section{Introduction}

China is a large developing country with nearly 900 million farmers. Rural medical security system can neither take the old path of developed countries, it is impossible to copy the current urban dependence on the state and social security benefits of the traditional model, it should be based on rural areas, to encourage farmers to move towards self-help and mainly in the power of collaboration, combined with a certain support in the state and society. This is a system with government organization, guidance, support and participated voluntarily by rural residents, collective and government multilateral financing, mainly to the poverty-stricken farmers' mutual aid medical security system. Party Plenum clearly states that "building a new socialist countryside is China's major historic task in the modernization process, you must follow 'the development of production, affluent life, rural civilization, clean and tidy village, democratic management' requirements, solid steadily pushing forward. "

The investigation team located in his hometown of three city a total of six rural villagers for the object. First objectively reflect the wishes of rural residents to participate in the new cooperative medical care at this stage, and affect the factors that villagers whether to participate or not through various indicators, in order to solve the participation process issues that arise and to provide reference for improving the villagers wish to join.

After a review of the extensive literature, our team selected six factors from a number of factors: personal financial status, the psychological factor, the participation awareness (including medical experiences and efficacy), provide local credibility the new rural cooperative medical system of hospitals, public opinion and propaganda, the new rural cooperative medical system the degree of perfection. The investigation based on the multiple linear regression analysis, factor analysis of a wish to join the quantitative analysis of the participation status of qualitative analysis and interpretation of the participation of each factor separately whether it will affect their willingness to effect size. The survey uses a combination of interviews and questionnaires manner 
in which the questionnaire based on the proportion of each urban sample.

Analysis of the population status of participation and enhancing the public participation will, conducive to the development of China's rural medical career, which is important to build a harmonious society. Therefore, the findings of this program will make a quantitative study to this investigation; we hope to provide data and theoretical support for the development of China's medical industry.

In the deepening of China's reform and opening up today, economic and social development gap between urban and rural areas growing, has become China's political, economic and social life of the outstanding problems. One important reason for this situation is the urban-rural dual structure. For a long time, rural areas provided a lot of resources in the country's industrialization and economic development ,funds, raw materials and at the same time a huge market, but failed to form a unified whole with the city entirely. Since the founding of fifty years, the focus of national construction and development in the city, resulting in social development pace of economic backwardness in the rural city, rural residents' income growth slower than urban residents, the income gap between urban and rural areas to increase social security system in rural areas construction is lagging behind. Figure 1 for the 1998 - 2008 average income gap between urban and rural China comparison chart:

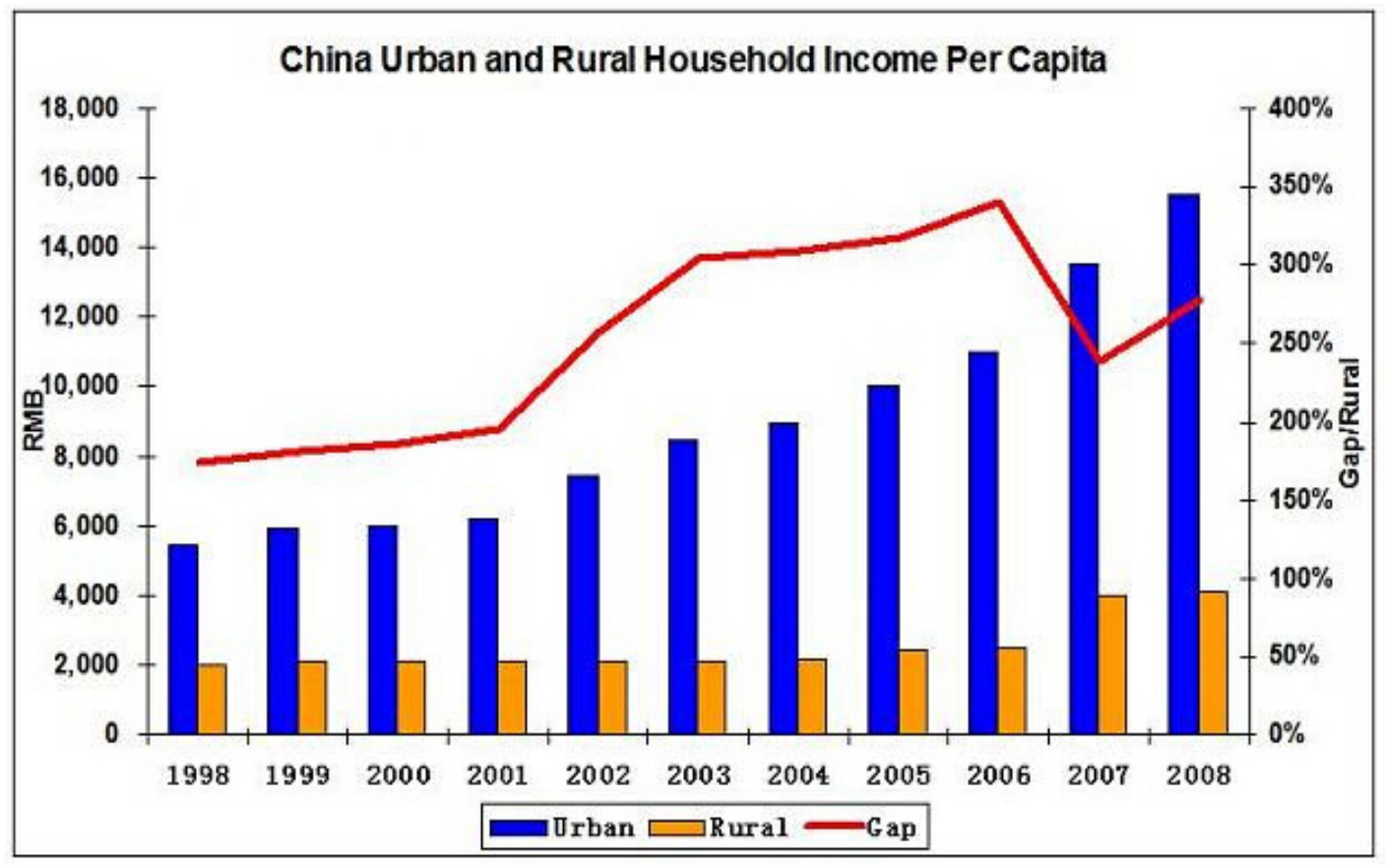

Figure 1

According to this situation, "the CPC Central Committee Decision on Further Strengthening Rural Health Work State Council" in October 2002 made it clear to gradually establish a new rural cooperative medical system, and a pilot since 2003, starting in 2006, the pilot counties (cities, districts) the number increased to about $40 \%$ of the counties (cities, districts) of the total, the central government and local governments to improve the amount of subsidy for participating farmers.

Liao Xiaoming, Jia Qingping (2007) reveals the impact of the new rural cooperative medical system and institutional issues, the main problem of sustainable development[1]. Ge Hengyun (2006) pointed out that compared with the traditional rural cooperative medical care system, the new rural cooperative medical system, the government's support to increase the intensity, highlighting the overall co-ordination of major diseases, the overall level is improved, and the voluntary participation of farmers, farmers enjoy the right to know and supervise[2].Xie Shengyuan (2005) proposed that the establishment of a new rural cooperative medical system should follow the "voluntary participation, multi financing," "pilot, and gradually promote" as well as "to set up a branch, to protect the appropriate" principle[3].Zhang Guangke (2009) pointed out that the risk of disease among rural residents in rural areas is different. In different compensation schemes, farmers face the risk of the disease, the share of the difference of the capacity of the disease[4].

Luo Li (2004), analysis the new rural cooperative medical system reduce the medical risk capacity, ease due to illness effects of poverty status of ability and medical expenses burden of 
income gap of rural residents and new rural cooperative medical system of farmers' income fairness influence etc., makes a more comprehensive evaluation[5].Xie Xiangyu (2007) et al, the new rural cooperative medical pattern and the system problems, in: one is "catastrophic" model easy to breed the adverse selection "; second is" guarantees the big sickness "fatal drawbacks embodied in giving up the most people of a new type of rural cooperative medical security responsibilities, many local farmers and even" minor money to cure and carry a serious illness "[6].

Research on the role of government in the new rural cooperative medical system. Xu Zhenghua (2005) people, the government's commitment to the responsibility of the new rural cooperative medical system arranged. The reason is that is the new rural cooperative medical security is a all the peasants should enjoy the basic rights, it has the characteristics of obvious mandatory, society, fairness, public[7].Li Peifu (2007) pointed out that in the new rural cooperative medical system government plays a leading role, it is the macroscopic plan makers; new cooperative medical propaganda, the organizer; new cooperative medical funds mainly raiser; new rural cooperative medical management; new cooperative medical supervisor[8].

Tangmin (2007) points out, the new type of rural cooperative medical care Wataru and the subject has diversified characteristics, the supply side of the government, farmers, rural cooperative medical organization, rural medical service supply and pharmaceutical products are the main body of the new rural cooperative medical system[9].Geng sciascia (2015) discusses the new rural cooperative medical system problems and the corresponding countermeasures[10]. Jiang Ailin (2007) taking Heilongjiang Province as an example to discuss the implementation of the new rural cooperative medical system[11].

\section{Research methods and procedures}

Based on this, our group investigated the rural residents in Zhejiang Province for five different provinces rural residents' views and details on whether there is to alleviate the financial burden of the role of research and analysis done.

Selecting research method is directly related to the level of efficiency survey, the reliability of the survey results. In order to get real specific information to better reflect the will of the people to donate, we will questionnaires and interviews with the combination of the population wish to join in the investigation, and interviews them with relevant health care system.

\section{The analysis of multiple linear regression models of the main factors}

The previously mentioned analysis of the actual situation results in six factors: economic status, the psychological factor, the participation awareness (including medical experiences and efficacy), provides local credibility of the new rural cooperative medical system in hospitals, public opinion and propaganda, the degree of perfection of the new rural cooperative medical system. According to the survey of the questionnaire, the quantitative analysis of the original qualitative data, as follows:

1)Assumption of the model variables and instructions:

Y: On behalf of farmers in the new rural cooperative will, to the will of qualitative ratings based on questionnaires set; A. Urgent requirement to participate-10 points;B Willing to participate-5 points;C. Unwilling to participate-(-5 points);D. Indifferent- 0 points

$\mathrm{X} 1$ : represent the factor of popularization degree.

According to the residents 'understanding about New Rural Co-operative Medical System, we assume that $\mathrm{A}$, very understanding, as 3;assume $\mathrm{B}$, know a part, as 2;assume $\mathrm{C}$, Not quite understand, as 1;assume D, Never heard of, as 0; If residents know about New Rural Co-operative Medical System, they will possibly participate in the new rural cooperative medical insurance. Otherwise, they won't participate in.

X2:represent the Perfection degree of the medical institution.

We divide dissatisfied, basic satisfaction and satisfaction respectively into 1,2and3. Assume that the Imperfect system will not have a large negative impact on Residents' desire, so we don't use 
negative value.

X3: represent Economic factors.

According to the five levels of income, we devide the value into 1, 2, 3, 4, 5.

First,we assume residents in each income level have energy to participate in the new rural cooperative medical insurance. In the following text we will then analyze the impact of the specific income levels.

X4: reprent the attitude to the Medical insurance, also called mental factor.

We divide useless, useful but not obvious, useful into -1,0,1.Assuming that the residents pursuit interest, so useless means represent will loss opportunity cost.

X5:represent participation awareness. 1 shows Reimbursement experience and 0 shows No reimbursement experience.

C: represents the error caused by various hybrid factors,

To make a supplement to the deviation of the model and the actual situation.

All of the virtual variables are only representative of the significance of the study, And cannot be completely representative of the actual meaning of the.

The following results are obtained by software processing.:

\begin{tabular}{|l|l|l|l|l|l|l|l|}
\hline & $\mathrm{C}$ & $\beta 1$ & $\beta 2$ & $\beta 3$ & $\beta 4$ & $\beta 5$ & $\beta 6$ \\
\hline Parameter & 0.792036 & 0.354848 & 1.055320 & -0.038227 & -0.223878 & 2.132570 & 0.568548 \\
\hline T Value & 1.216064 & 1.686442 & 3.195671 & -0.258213 & -0.743181 & 5.623831 & 2.036296 \\
\hline
\end{tabular}

\begin{tabular}{|c|c|c|c|c|}
\hline Variable & Coefficient & Std. Error & t-Statistic & Prob. \\
\hline $\mathrm{C}$ & 0.792036 & 0.651311 & 1.216064 & 0.2246 \\
\hline $\mathrm{X} 1$ & 0.354848 & 0.210412 & 1.686442 & 0.0925 \\
\hline $\mathrm{X} 2$ & 1.055320 & 0.330234 & 3.195671 & 0.0015 \\
\hline X3 & -0.038227 & 0.148045 & -0.258213 & 0.7964 \\
\hline $\mathrm{X} 4$ & -0.223878 & 0.301242 & -0.743181 & 0.4578 \\
\hline $\mathrm{X} 5$ & 2.132570 & 0.379202 & 5.623831 & 0.0000 \\
\hline $\mathrm{X} 6$ & 0.568548 & 0.279207 & 2.036296 & 0.0424 \\
\hline R-squared & 0.136059 & \multicolumn{2}{|c|}{ Mean dependent var } & 4.339623 \\
\hline Adjusted R-squared & 0.123629 & \multicolumn{2}{|c|}{ S.D. dependent var } & 3.408755 \\
\hline S.E. of regression & 3.191096 & \multicolumn{2}{|c|}{ Akaike info criterion } & 5.174978 \\
\hline Sum squared resid & 4246.350 & \multicolumn{2}{|c|}{ Schwarz criterion } & 5.241836 \\
\hline Log likelihood & -1090.095 & \multicolumn{2}{|c|}{ Hannan-Quinn criter. } & 5.201393 \\
\hline F-statistic & 10.94534 & \multicolumn{2}{|c|}{ Durbin-Watson stat } & 1.646607 \\
\hline Prob(F-statistic) & 0.000000 & & & \\
\hline
\end{tabular}

According to a preliminary regression results, we find that the constant $C$ and $\beta 3, \beta 4$ was not significant, which reflects these factors may have no other relevant factors to the residents' willingness of participation or the willingness of participation is extremely small problems in the data reflected. Due to the X3 represents the income level of resident, the utility of this factor is not significant that residents in the corresponding income level, basically have energy participation, reflects the residents get due protection from the side. Also because of X4 represents the attitude to the Medical insurance, the variable is not significant, indicating that the residents in the psychology 
on the participation of the will to a large extent by other psychological factors, such as to keep up with the Joneses, follow the trend of psychological. And then, we eliminate not significant variables and constants to do regression. And get the following results.

\begin{tabular}{|c|c|c|c|c|}
\hline Variable & Coefficient & Std. Error & t-Statistic & Prob. \\
\hline $\mathrm{X} 1$ & 0.521435 & 0.164352 & 3.172663 & 0.0016 \\
\hline $\mathrm{X} 2$ & 1.202373 & 0.276705 & 4.345326 & 0.0000 \\
\hline $\mathrm{X} 5$ & 2.319308 & 0.349855 & 6.629336 & 0.0000 \\
\hline X6 & 0.567276 & 0.278005 & 2.040524 & 0.0419 \\
\hline R-squared & 0.131604 & \multicolumn{2}{|c|}{ Mean dependent var } & 4.339623 \\
\hline Adjusted R-squared & 0.125401 & \multicolumn{2}{|c|}{ S.D. dependent var } & 3.408755 \\
\hline S.E. of regression & 3.187867 & \multicolumn{2}{|c|}{ Akaike info criterion } & 5.165971 \\
\hline Sum squared resid & 4268.249 & \multicolumn{2}{|c|}{ Schwarz criterion } & 5.204176 \\
\hline Log likelihood & -1091.186 & \multicolumn{2}{|c|}{ Hannan-Quinn criter. } & 5.181065 \\
\hline Durbin-Watson stat & 1.663681 & & & \\
\hline
\end{tabular}

$$
\begin{array}{ccccc}
\mathrm{Y}=\mathrm{X} 1 * 0.521435+\mathrm{X} 2 * 1.2102373+\mathrm{X} 5 * 2.319308+\mathrm{X} 6 * 0.567276+\mathrm{e} \\
\mathrm{t} & 3.172663 & 4.3475326 & 6.629336 & 2.040524
\end{array}
$$

According to the results, we found that Public reliability of designated hospitals has the biggest impact on residents' willingness to participate. Followed by the improvement of the new rural medical system. This result can be explained reasonably. If point hospital medical level and medical facilities are recognized by people, people will participate in insurance. of course, most of the local hospitals are better , so people are more recognized, People's psychological expectations will be more positive if they have a injury after the insurance .Influence of new rural medical system's perfection degree to participating in the insurance can also get a reasonable explanation. Any system only relatively perfect to a full range of vital interests are implemented to ensure farmers, so the factors that affect the willingness of participation also is significant

\section{Conclusion and the existing problems}

1) in the psychological factors, the new rural cooperative medical care in the hearts of the residents of the utility factor is only a part of the factors, there are many other psychological factors will affect their wishes.

2) in terms of economic factors, the amount of income although less obvious impact on the participation of the wishes of the residents, but due to the income effect is very convincing. Our panel is exposed to the limitations of data collection and data collection.

3 ) credibility with the new rural cooperative medical system in the perfect degree of residents participation will have tremendous impact that residents are more willing to see population legend and reasoned written policies. Residents are more willing to accept acceptable to all things. On the other hand also reflects the residents of the government will not blindly follow, but also reflects the residents of the government in the presence of a certain question.

4) in the cognitive level, because the residents of the new rural cooperative medical care in the understanding of the average level is lower, tend to focus, so the residents will be in the influence of the level of agreement, making the value of the coefficient is relatively small.

\section{Policy recommendations}

First, through various channels, improve the participation rate of farmers, expand the coverage of 
the new rural cooperative medical system.

Two, the establishment of scientific and reasonable financing standards, diversified financing channels, appropriate financing levels and financing model.

Three, the innovation mechanism, increase the supervision of new rural cooperative medical.

Four, the establishment of scientific and effective reimbursement mechanism, improve the efficiency of reimbursement links, to mobilize the enthusiasm of the peasants, strengthen the reimbursement system reform, science and the development of standards for reimbursement, adopt innovative compensation mechanism.

Five, increase the construction of rural cooperative medical care infrastructure, improve the overall quality of the new rural cooperative medical team. At present, the rural cooperative medical care is poor, the infrastructure is backward, the farmers' medical treatment environment is not optimistic. The quality of rural cooperative medical care system is generally low, and the hierarchy structure is unreasonable.

\section{Acknowledgement}

In this paper, the research was sponsored by the soft science key project of Zhejiang Province (2014C25032) and the National College Students' innovation and entrepreneurship training program.

\section{References}

[1] Liao Xiaoming, Jia Qingping. Analysis of the new type of rural cooperative medical system based on system dynamics [J]. China Administration, 2007, (9): 66-69

[2] Ge Huanyun. Research on the sustainable development of new rural cooperative medical system [J]. China health economics, 2006, (12); 5-7

[3] Xie Shengyuan. The historical retrospect and development of the system of rural cooperative medical system: M. 2005, (4): 44-46

[4] Zhang Guangke. Study on the risk sharing capacity of the new type of rural cooperative medical system (M.), 2009, (9): 70-76

[5] Luo Li. Research on the evaluation of the new type rural cooperative medical system [R]. 2004,12

[6] Xie Xiangyu. The new rural cooperative medical insurance system compensation [J]. model of economic reform, 2007, 4: 152-155

[7] $\mathrm{Xu}$ Zhenghua. The government responsibility in the new rural cooperative medical system $\mathrm{M}$. Journal of East China Institute of Technology (SOCIAL SCIENCES), 2005, (1): 85-88

[8] Li Peifu. The leading position of the government in the construction of new rural cooperative medical system ([J].), 2007, (3): 93-94

[9] Tang Min, Wu Benyin. New Rural Cooperative Medical System Innovation M? Economic issues exploration, 2007, (3): 118-123

[10] Geng [J].. Sciascia problems and Countermeasures of legal system and social existence, the new rural cooperative medical system 2015, 11 (11).

[11] Jiang Ailin, Li Gang. Study on the implementation of the new rural cooperative medical system -- Taking Heilongjiang Province as an example [J]. Gansu social science, 2007, fourth (4): 177-179. 